\section{Un aeropuerto en el Conurbano. Para una lectura histórica y cultural de un territorio en disputa}

Daniela Soldano

Instituto del Conurbano, Universidad Nacional de General Sarmiento, Argentina.

\author{
María Gimena Perret Marino \\ Instituto del Conurbano, Universidad Nacional de General Sarmiento, Argentina.
}

Recibido: 13 de diciembre de 2018. Aceptado: 18 de marzo de 2019.

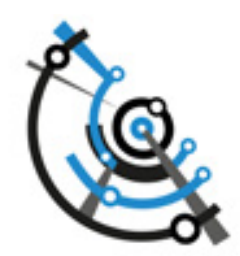

\title{
Resumen
}

A inicios del siglo XX, El Palomar combinaba un paisaje de quintas, chacras y tambos y un primer núcleo urbano cercano a la estación del ferrocarril Buenos Aires al Pacífico. Como en el Conurbano en su conjunto, pero acentuado quizá por esta condición de relativa lejanía respecto de la localidad cabecera del municipio, fueron las instituciones barriales las que asumieron la gestión de la provisión de servicios urbanos. Desde su conformación, dos instituciones militares conllevan un alto poder de estructuración del territorio, su vida política y formas de sociabilidad: el Colegio Militar de la Nación de 1937 y la Primera Brigada Aérea, conocida desde 1949 como la Base. Cien años después, esta última infraestructura se vio involucrada en el centro de una intensa polémica, cuando el proyecto de autorizar la aeronavegación comercial e inaugurar el Aeropuerto de El Palomar alteró el clima político local. Este artículo analiza desde una perspectiva histórica y cultural estas disputas atendiendo al imaginario urbano en el cual se inscriben. A partir del trabajo con fuentes documentales y entrevistas a residentes, procura reponer en el debate la historia socio-cultural de la base aérea (y su gravitación) como condición de fragua -de identidad- de este suburbio.

\section{An airport in the Conurbano. For a historic and cultural reading of a territory in dispute}

\section{Abstract \\ At the beginning of the 20th Century the landscape of El Palomar combined farms, smallholdings, and dairy farms, with an urban center close to the railway station. As in the rest of Buenos Aires' suburbs -but especially here, given the relative}

Palabras clave

Aeropuerto de El Palomar Historia del conurbano bonaerense

Historia social y cultural de la ciudad

Sociedades de Fomento Imaginarios urbanos

Palavras-chave

Aeroporto do El palomar História do conurbano de Buenos Aires

História social e cultural da cidade

Sociedades de desenvolvimento comunitário

Imaginários urbanos
Keywords

El Palomar Airport History of Suburban Buenos Aires

Urban socio-cultural history

Grassroots movements Urban imaginaries 
remoteness of this town to the capital city of the district- it was the neighborhood institutions who managed the provision of urban services to the locality. Since its inception, two military institutions were key to the structuring of the territory of El Palomar, its political life and sociability patterns: the National Military Academy (Colegio Militar de la Nación) and the First Air Brigade (Primera Brigada Aérea), founded in 1912, and known since 1949 as "la Base" ("the Base"). One hundred years later, a project to inaugurate there the El Palomar Airport, for commercial air navigation, altered the local political climate. This article analyzes the disputes this project generated among the local society from a historical and cultural perspective. Through local primary sources and in-depth interviews with local inhabitants, it seeks to reinstate in the debate the socio-cultural history of la Base as a central trait of the district's identity.

\section{Introducción}

A inicio del siglo XX, como en buena parte del Conurbano Bonaerense, El Palomar combinaba un paisaje de quintas, chacras y tambos y un primer núcleo urbano cercano a la estación del ferrocarril Buenos Aires al Pacífico. La localidad en cuestión se localizaba en la periferia del partido de Morón lindante con Ciudad Jardín Lomas del Palomar, partido de San Martín (en la actualidad Tres de Febrero).

Como sucede en el Conurbano en su conjunto, pero acentuado quizá por esta condición de relativa lejanía respecto de la localidad cabecera del municipio, fueron las instituciones barriales -una multiplicidad de juntas vecinales, bibliotecas y sociedades de fomento- las que asumieron la representación de los intereses de los ciudadanos y la gestión de la provisión de servicios urbanos frente a las distintas autoridades.

En ese derrotero, y construyendo también una condición particular, la vida cotidiana de la localidad se vio marcada por la presencia de dos instituciones militares con un alto poder de estructuración del territorio, su vida política y formas de sociabilidad: el Colegio Militar de la Nación que abrió sus puertas en 1937 y la Primera Brigada Aérea, heredera de la Escuela de Aviación Militar instalada allí en 1912 y que desde 1949 comenzó a ser referida socialmente como la Base (Fuente: entrevistas a residentes de la localidad y fuentes documentales del Archivo Histórico de Morón, Caja Palomar)

Cien años después, esta última infraestructura se vio involucrada en el centro de una intensa polémica, cuando el proyecto de autorizar la aeronavegación comercial e inaugurar el Aeropuerto de El Palomar alteró el clima político local. En efecto, desde los primeros momentos la iniciativa generó tanto posiciones de resistencia -que podrían ser denominadas conservadoras o conservacionistas- como apoyos fundamentados en un argumento modernizador. Ambas coagularon con fuerza en la escena pública hacia 2017, cuando se produce el inicio de las actividades del aeropuerto y tanto las rutas de acceso a la localidad como el paisaje de su centro comercial y manzanas lindantes a la estación, fueran invadidas por una señalética en furioso amarillo fosforescente con un avión en su centro.

Este artículo propone mirar estas disputas atendiendo al imaginario urbano en el cual se inscriben. A partir del trabajo con fuentes documentales y entrevistas a residentes, procura reponer la historia de la Base Aérea (y su gravitación social y urbana) como condición de fragua de este suburbio. En efecto, como se argumentará, El Palomar está marcado tanto por el carácter bucólico y pastoril que prometían a potenciales habitantes las compañías loteadoras de tierras hacia las décadas de 1930 
y 1940, como por el relato de conexión y modernidad que confería la presencia de los aviones militares en la vida cotidiana, en una combinación sustantiva con el rol de autoridad e intervención social y urbana que asumía la Base frente a la fragilidad y lejanía del Estado provincial y municipal.

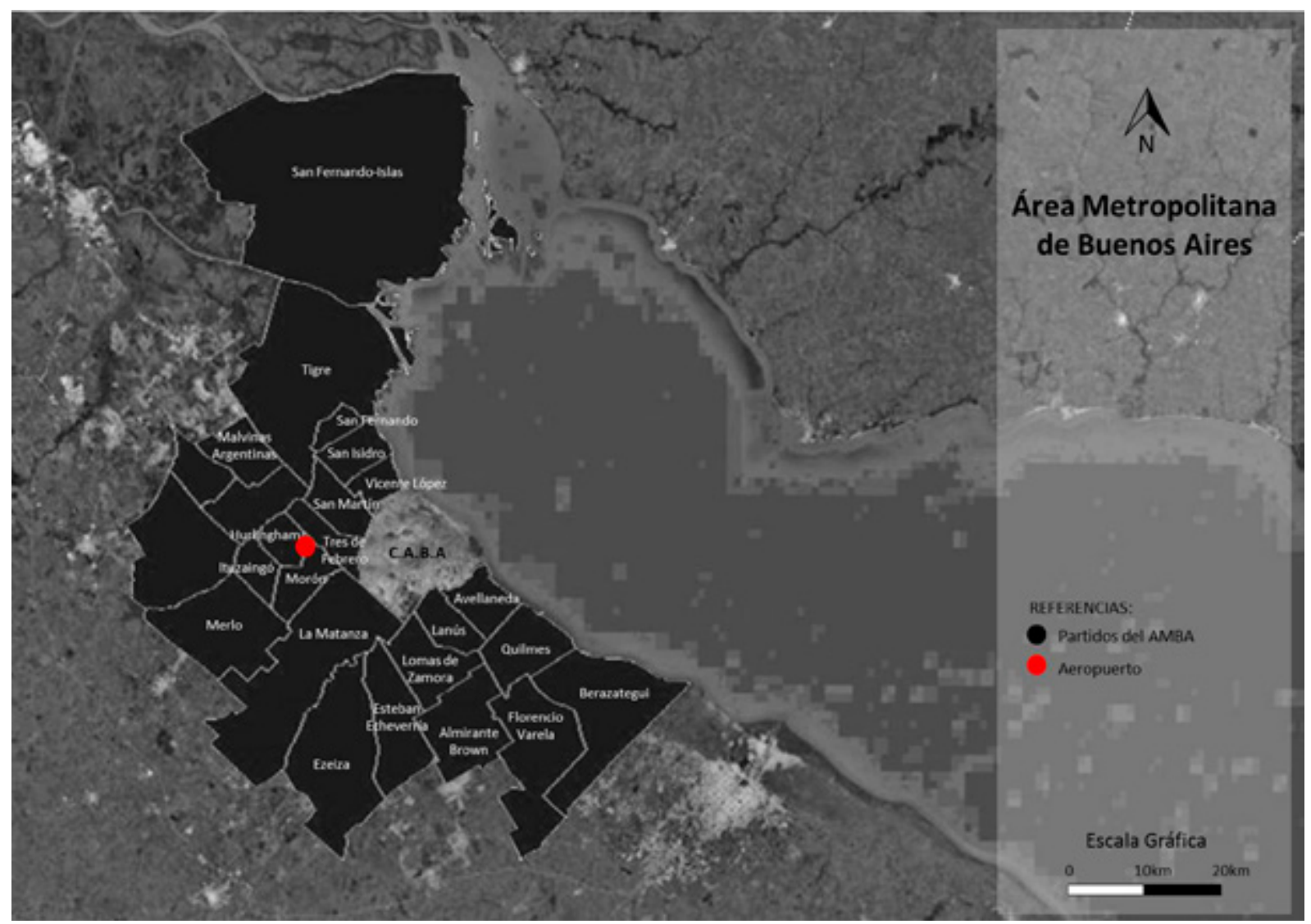

Figura 1. Ubicación del aeropuerto de El Palomar en el AMBA. Fuente: Elaboración propia sobre la base de imagen satelital Google Earth e IDE Conurbano. Universidad Nacional de General Sarmiento. (2016)

\section{Un territorio en disputa}

Noche fría y lluviosa de inverno en Ciudad Jardín, partido de Tres de Febrero. Un grupo de habitantes y miembros de organizaciones sociales participan en la sede de la biblioteca del viejo barrio F.I.N.C.A ${ }^{1}$ de una reunión convocada a propósito de los múltiples efectos que el inicio de la explotación comercial de las instalaciones de la base aérea está trayendo a la comunidad. La organización se llama Isla Verde y su rol consiste en demostrar que la actividad de la empresa low cost, Flybondi, es ilegal y conlleva una serie de impactos ambientales de múltiple tenor, y que generará la destrucción del bosque nativo y del humedal, afectando el hábitat de los pájaros y altos niveles de contaminación sonora y atmosférica. En efecto, parte crucial de la disputa gira en torno a si el predio donde se emplaza la Base Área es o no un bosque nativo (de serlo, se encuentra bajo el amparo de la ley nacional de bosques y debe ser resguardado) o si se trata -como sostiene el argumento de la empresa y del Ministerio de Transporte- de un ambiente ya intervenido por la mano del hombre y, por ende, habilitado para cualquier uso.
1. Nombre de la constructora que planificó y emplazó a la Ciudad Jardín, modelo en la región desde los años 40 . Se trató de una estructura con servicios urbanos y sociales a la que arribó la clase media que alquilaba en la ciudad de Buenos Aires, a través del crédito a bajo costo y de fácil acceso (Soldano y Perret Marino, 2017). 


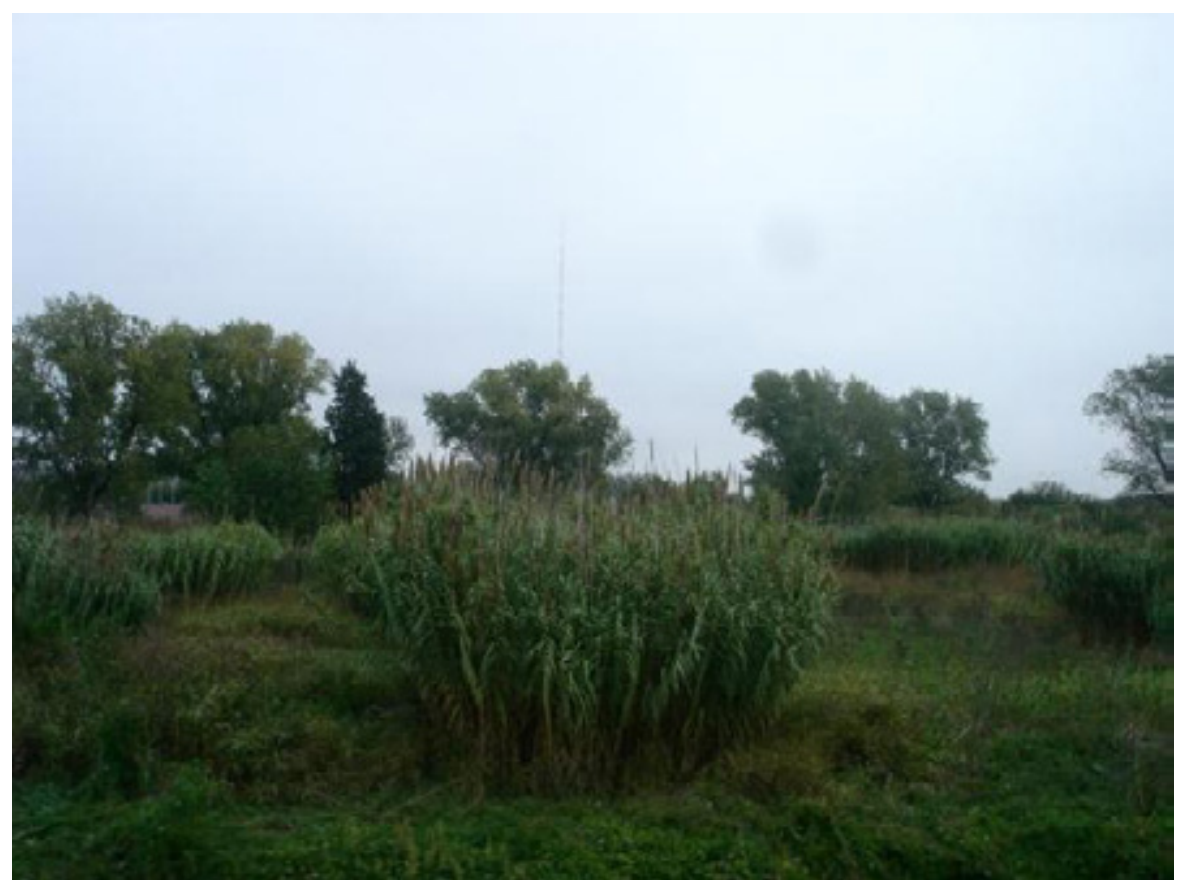

Figura 2. Paisaje natural de la zona de El Palomar. Fuente: Trabajo de campo (2016)

Están reunidos ingenieros, urbanistas, abogados, miembros de organizaciones ambientalistas, un delegado gremial de los trabajadores aeronáuticos y vecinos preocupados por la preservación del área. En la conversación se retoman los argumentos de corte ambiental que se esgrimieron en la audiencia pública realizada en la Biblioteca Popular Juan Manuel Giuffra de El Palomar (La Nación marzo 2018) en la que participaron 140 personas y se expresaron 95 oradores. Promediando la reunión, el delegado gremial reivindica la voz de los trabajadores en el debate:

¿Se preguntan qué hace aquí un trabajador aeronáutico? ¿Somos nosotros una especie de románticos que nos oponemos al progreso? No, queremos un verdadero progreso, pero el argumento del Ministerio de Transporte sobre la Argentina yendo hacia la modernidad con más argentinos tomando aviones es una media verdad. Todo lo que no está dicho es importante. ¿Por qué instalar un aeropuerto acá en Palomar? ¿Cuándo lo decidieron y con qué argumentos? Se trata de pura improvisación, para bajar costos, sin inversión, sin asumir riesgos...

Un referente central, que se ha encargado de los escritos presentados al fiscal de la causa, se lamenta por el levantamiento del recurso de amparo que detuvo las tareas del aeropuerto en enero de 2018 y explica a los presentes las complejidades del tema. Señala que no se toma en cuenta que el municipio y la provincia son quienes se responsabilizan por los problemas de acceso y congestión vehicular que se ha generado en horas pico, por la gestión de los residuos que llevan y traen los aviones y los costos de la operación (y riesgos) que supone la operación aeroportuaria en el espacio local.

El señalamiento es clave porque permite iluminar la naturaleza multiescalar del conflicto. En efecto, los riesgos y dilemas de su operación suceden en el territorio de proximidad, pero la jurisdicción con autoridad sobre el aeropuerto es nacional: la Administración Nacional de Aviación Civil (ANAC), organismo descentralizado dependiente del Ministerio de Transporte de la Nación. ${ }^{2} \mathrm{Ni}$ es Estado municipal ni el provincial están en condiciones de tomar las decisiones importantes aunque se vean
2. El Organismo, creado en 2009, implicó el pase a la órbita civil de las funciones que venía cumpliendo el Comando de Regiones Aéreas de la Fuerza Aérea Argentina y la Subsecretaría de Transporte Aerocomercial, dependiente hasta el 2012 del Ministerio de Planificación Federal, pasando a depender a partir de ese año del Ministerio del Interior y Transporte. El proyecto incluía disolver el ente autárquico llamado Organismo Regulador del Sistema Nacional de Aeropuertos -ORSNA- y traspasar sus funciones a la ANAC, pero esto último no sucedió. 
afectados directamente por sus consecuencias y sean la cara visible del asunto frente a los damnificados. El conflicto en torno al aeropuerto permite apreciar, así, un complejo sistema de actores que pujan por imponer sus visiones en torno al control de los territorios y a las potenciales alternativas de resolución de los problemas (Subra, 2012/13:45).

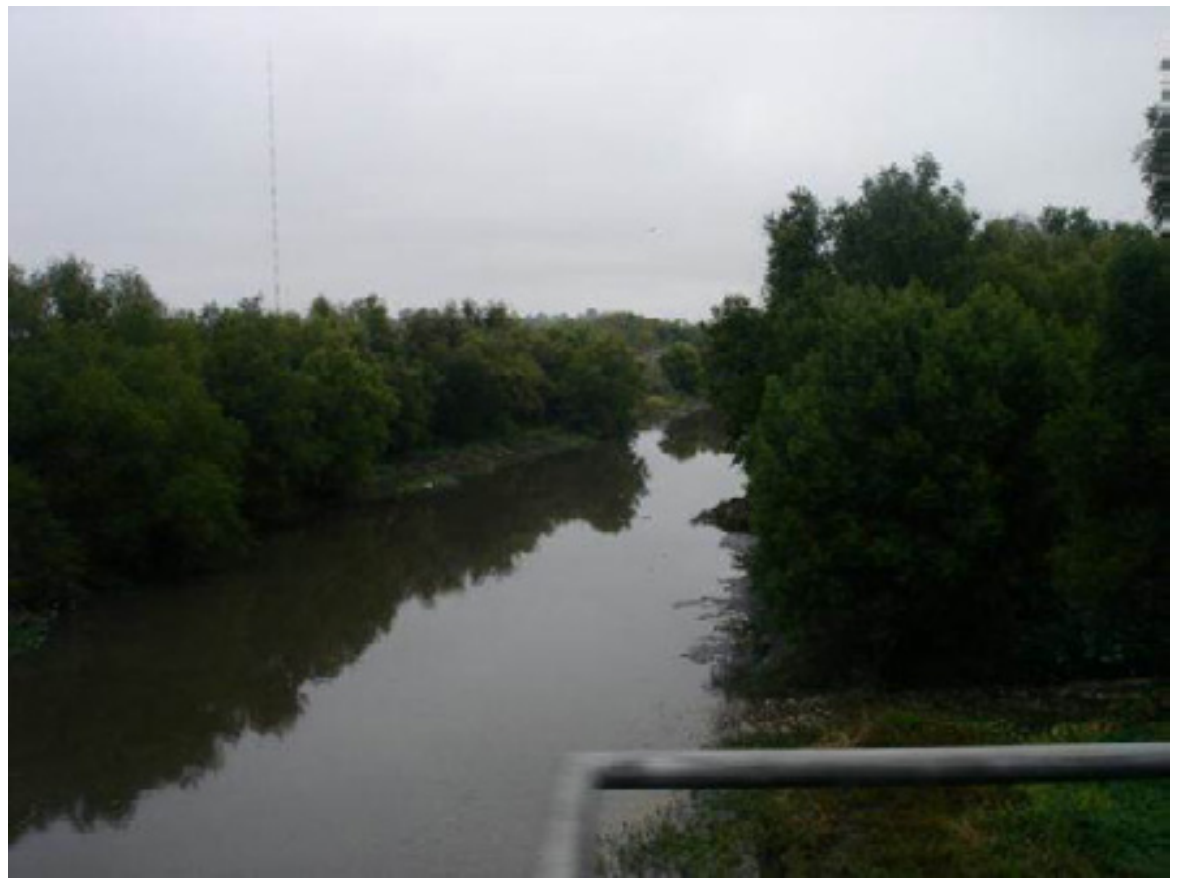

Figura 3. Arroyo Morón, lindante con la Base aérea. Fuente: Trabajo de campo (2016)

A estos argumentos críticos planteados en la reunión de corte ambientalista, se suman los patrimoniales y socioeconómicos. Según los primeros, se trata de un sitio que debe ser protegido y conservado debido a los delitos de lesa humanidad y violación de los derechos humanos allí cometidos durante la última dictadura militar. Unos meses después de iniciadas las movilizaciones y recursos de amparo por diversas organizaciones de vecinos de la localidad, como Stop FlyBondi, el juzgado federal de San Martín les confirmó que la Base Aérea de El Palomar es un sitio protegido por la ley 26.691 de Preservación, Señalización y Difusión de los Sitios de la Memoria y que por tanto el desarrollo de la aeronavegación comercial es ilegal. En efecto, con las obras de infraestructura que supone el acondicionamiento de la Base como aeropuerto comercial, se podría destruir o alterar documentación (pruebas judiciales) para investigar los llamados vuelos de la muerte que se afirma despegaban desde allí durante la última dictadura militar. ${ }^{3}$

Para el segundo, la operación aeroportuaria redundará en una baja considerable del valor del suelo y en la pérdida de un estilo de vida pueblerino caracterizado por la tranquilidad y sus espacios verdes.

Además de la organización Isla Verde, dos colectivos multiactorales - Stop fly bondi y No al aeropuerto trucho - dieron forma a núcleos de acción de resistencia diversos y abiertos en los que cobra protagonismo la voz de los colegios de la zona y de los

3. En noviembre de 2017 y febrero de 2018 se realizaron (entre otras acciones) dos marchas bajo la consigna No al aeropuerto trucho de El Palomar, en las que este argumento se pone en valor a partir de la presencia de Nora Cortiñas (Madre de Plaza de Mayo) y la madre de un adolescente de 14 años secuestrado durante la dictadura militar (La izquierda Diario 2018). residentes en general. 


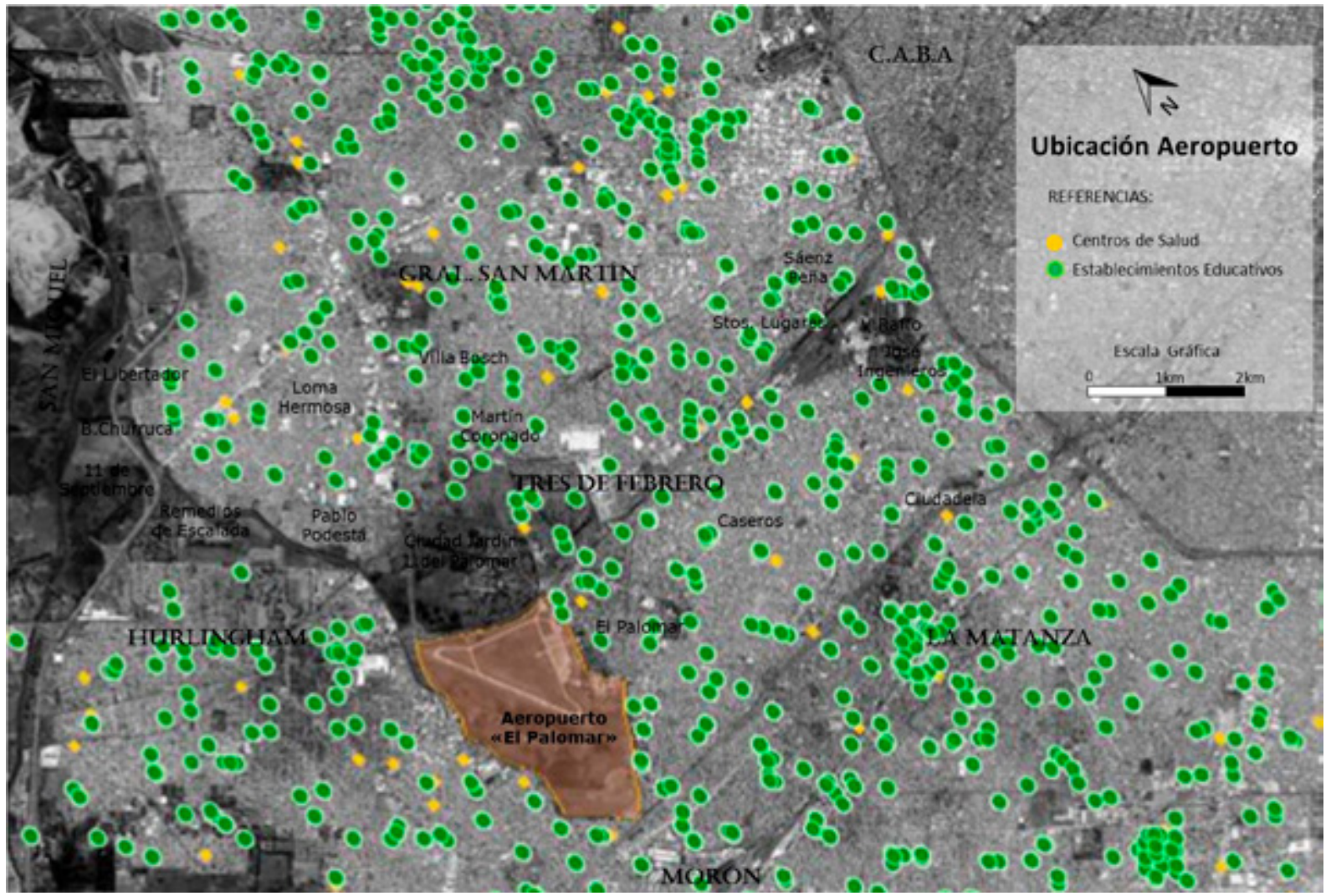

Figura 4. Localización de establecimientos educativos y sanitarios, localidades y aeropuerto de El palomar. Fuente: Elaboración propia sobre base de imagen satelital Google Earth e IDE Conurbano. Universidad Nacional de General Sarmiento. (2016)

Lo publicado en un portal de información del partido de Hurlingham el día 23/04/18 es elocuente de lo anterior:

Las consecuencias del impacto ambiental negativo que causa el incremento de la frecuencia de los vuelos comerciales de Flybondi desde la Base Militar de El Palomar aumentan cada día. Las comunidades educativas de varias escuelas de Hurlingham dieron a conocer las graves complicaciones que les genera la situación. En estos días han surgido numerosos reclamos de la gran cantidad de escuelas, colegios yjardines de infantes que se ubican en Hurlingham. Es que se encuentran justo en la línea de aterrizaje y despegue de la low cost, ubicados a escasísimos metros en línea recta del fin de la pista. (...). Durante los primeros días de funcionamiento de Flybondi en $\mathrm{El}$ Palomar, los despegues de los aviones eran realizados en sentido hacia El Palomar y los aterrizajes eran efectuados sobre Hurlingham. Sin embargo, en las últimas semanas advirtieron que mientras los aterrizajes se realizan sobre el mismo lugar, a eso se le han sumado los despegues. De esta manera, se duplicó la contaminación de fuertes ruidos de los aviones junto con la contaminación atmosférica de la estela que emanan. Al respecto ya existen denuncias de que producen un fuerte e irrespirable olor a combustible que se teme sea cancerígeno. Asimismo, los alumnos y docentes padecen un aumento de la distracción, falta de concentración y problemas de disciplina de los chicos. (...) Varios puntos han sido denunciados como violación a las normas de seguridad que cualquier aeropuerto debe tener, más aun tratándose de la cercanía con los espacios como viviendas, instituciones educativas, clubes de barrio y plazas (Portal Información Hurlingham, 2018). 

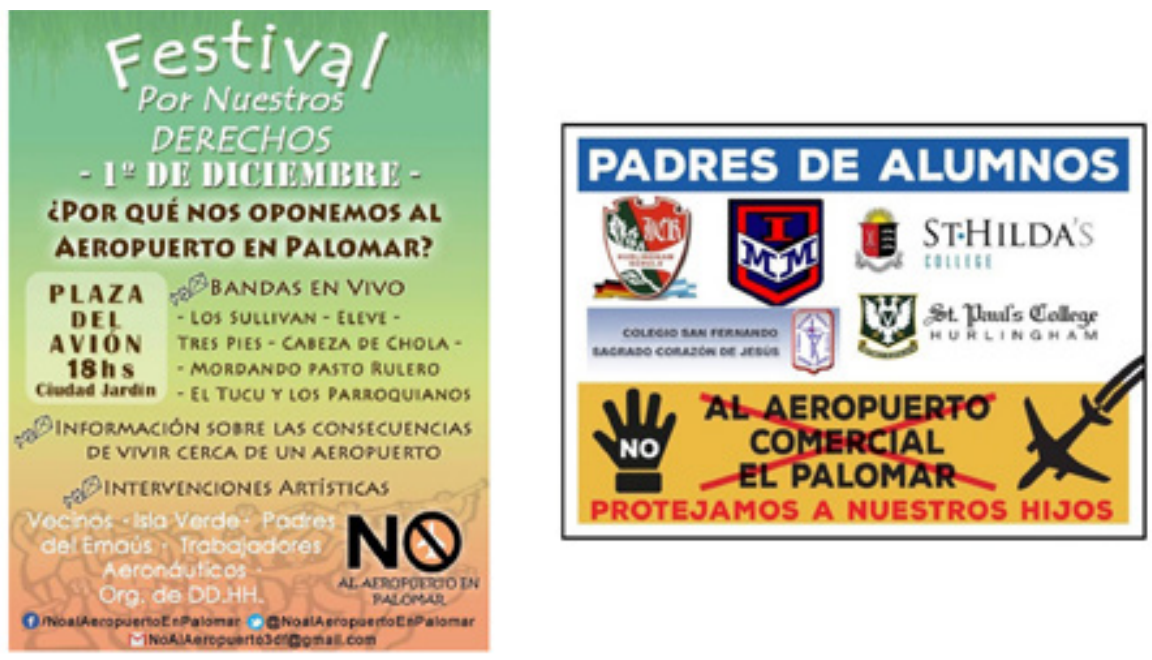

Figura 5. Material de difusión de actividades en contra del aeropuerto comercial. Fuente: Trabajo de campo (2018)

El colectivo Stop Flybondi Oficial realizó a comienzos de año una presentación ante el fiscal Di Lello en los tribunales de Comodoro Py y solicitó el cierre definitivo de la Base Militar El Palomar. En ésta se enumeran los distintos problemas que se han suscitado en las instalaciones del aeropuerto, así como desperfectos de la línea aérea tales como aterrizajes fallidos, cortes en el suministro eléctrico, suspensión de vuelos, despegues abortados, o vuelos cancelados.

El Palomar nunca debió ser utilizado como aeropuerto comercial, ya que es imposible garantizar las condiciones mínimas de seguridad (...) se trata de un "riesgo mortal" que corren a diario los más de 15 mil chicos que estudian a en escuelas ubicadas a metros de la pista destacándose el colegio Emaús con más de 3000 chicos ubicados en la línea recta a tan solo 650 metros del final de pista de donde salen los aviones Flybondi.

La polémica local incorpora, así, dos dimensiones del riesgo: el riesgo para los moradores y el riesgo para los usuarios. El martes 10 de Julio de 2018, por citar un caso que tomó notorio estado público, el cese de todas las actividades dejó 5000 pasajeros en El Palomar cuyos vuelos fueron reprogramados para días posteriores desde Ezeiza, lo que provocó un estallido de furia frente a los empleados. El portal de noticias LMNeuquén así lo describía:

La gresca tuvo réplicas en distintas ciudades del interior del país como Iguazú, Tucumán y Posadas con cientos de pasajeros que estallaron de bronca al cancelarse todos los vuelos que tenían como destino El Palomar (...) Al final del día la firma subió en su web un comunicado donde detalló la totalidad de vuelos cancelados debido a las "condiciones climáticas" y anunciaron que para el domingo por lo menos cuatro vuelos saldrían desde el Aeropuerto de Ezeiza y no desde El Palomar. Para mayor desconcierto de los pasajeros a los cuales se los cambió de terminal, Aeropuertos Argentina 2000 no informó en su página web oficial ninguno de los vuelos de Flybondi que operaron desde Ezeiza. Con este nuevo escándalo, cobra fuerza el reclamo de los vecinos de Morón, Hurlingham, Tres de Febrero, La Matanza y San Martin, quienes masivamente rechazan el uso comercial de la base militar al verse perjudicados por la contaminación sonora y atmosférica, al tener un aeropuerto a pocos metros de sus viviendas (LMNeuquén, 2018). 
Mientras tanto, el argumento oficial seguía enfatizando el progreso que trae consigo el cambio de uso de las instalaciones. En las declaraciones públicas del ministro de transporte de la nación así como en las de las autoridades locales, se destacan los beneficios de la conexión de El Palomar con la Argentina y el mundo, así como las externalidades positivas que derivan de la obra pública asociada al aeropuerto, obras que durante décadas estuvieron postergadas. Como describía un portal de noticias oficial del partido de Morón:

Desde mitad de año arrancó la repavimentación total de las distintas arterias, avenidas y calles destinadas al tránsito de transporte público de pasajeros y transporte de cargas. Ya finalizaron los trabajos de repavimentación sobre la Avenida Marconi entre Urquiza y Ferrari y se están realizando bacheos con hormigón en la Av. Marconi entre Ferrari y la colectora de la Autopista Acceso Oeste (Municipio de Morón, 2018).

El estado se hace presente al arreglar plazas, mejorar o hacer veredas y electrificar el Tren San Martín, como destaca una vecina histórica de la localidad:

Gracias al aeropuerto arreglaron Marconi, que desde siempre estuvo rota, abandonada y en el último tiempo hasta lomadas tenía, fijate que un día uno se cayó en uno de los pozos que tenía (Entrevista a habitante de El Palomar).

En esta misma línea, una voz menos estridente y sin canal de expresión visible apoya la operación comercial de la base: son los comerciantes, que ven con agrado el aumento de movimiento y circulación de personas.

Parece que nadie de acá tomara uno de estos aviones, no ven la parte buena del progreso, es que la discusión sobre el aeropuerto quedó atrapada en la grieta de la política a nivel nacional. La aceptación o no del aeropuerto se transformó en adhesión o no a Cambiemos o al kirchnerismo (Entrevista a habitante de El Palomar).

Otro residente de El Palomar desde hace más de 50 años y que trabaja en la escuela nocturna señala la expectativa de inserción laboral de la gente de la localidad como pasa en Ezeiza. Así, los argumentos "modernizadores" abonan el carácter positivo de un cambio que saca al barrio de la postergación:

Nadie te cuenta lo bueno que está estar en Córdoba en una hora, cuando antes tenías que llegar hasta Aeroparque y pagar una fortuna (Entrevista a habitante de El Palomar).

Otro entrevistado, un médico de 77 años y con formación autodidacta en ecología explica que el bosque donde está emplazada la base no es nativo y que su principal atributo es que desde el origen fue tocado por el habitante del nuevo conurbano, lo que se hace visible en la vegetación. Explica que los cañaverales que están por todos lados dan cuenta de la actividad de los quinteros inmigrantes de las primeras décadas del siglo XX (Entrevista a habitante de Villa Tesei).

Como el mensaje en una botella que el mar zarandeó durante las décadas del siglo $\mathrm{XX}$, los testimonios de los habitantes de la localidad entrevistados traen también al presente reflexiones sobre la Base que nos permiten comprender su sentido histórico. Este argumento no plantea necesariamente una polémica con el resto. Solo aparece para recordar al lector de los imaginarios urbanos qué lugar ocupó este emplazamiento en el momento en el que se erigió la comunidad. 
Reconstruir e interpretar imaginarios urbanos implica situar en primer plano la forma de habitar y sentir la ciudad y valorar su calidad de vida. Los imaginarios son tanto la arena de lucha por la imposición de significados y usos legítimos, como el reservorio estético desde el cual se construye el paisaje así como una potente matriz de categorías identitarias (Brubaker y Cooper, 2001; Guateros Trujillo, 2006; Gravano, 2006; Delgado, 2011). Asimismo, los imaginarios se constituyen sobre las experiencias espaciales cotidianas de los habitantes, constituyendo un cosmos heterogéneo y atravesado por polémicas y conflictos (Silva, 2008).

Teniendo en cuenta este encuadre conceptual, este artículo se pregunta: ¿se trata del mismo aeropuerto? ¿Qué significaba la Base en los orígenes? ¿Qué tanto está presente en la actualidad?

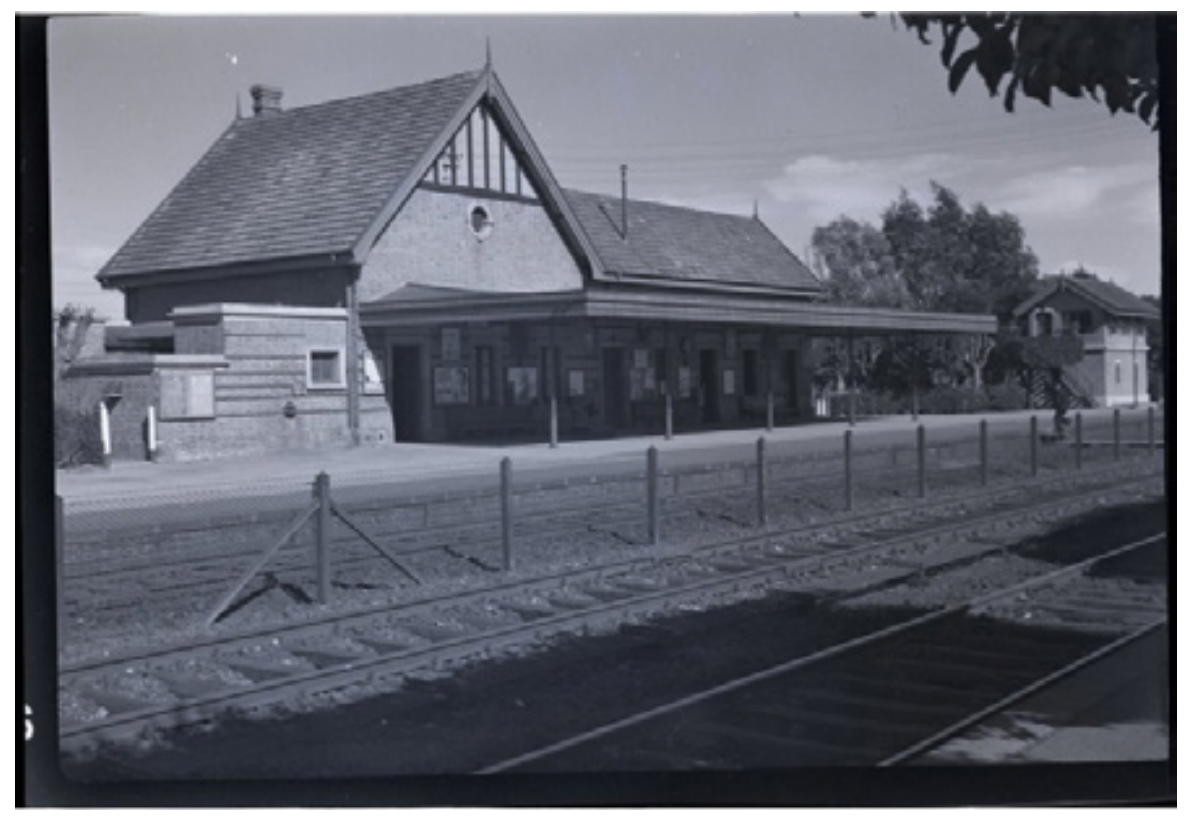

Figura 6. Estación El Palomar. Fuente: AGN. Circa 1930

\section{El Palomar, la base aérea y el fomento en la constitución de la experiencia suburbana}

Vas a ver, vos preguntá, en todas las familias de la zona hay algún recuerdo de ir a la base a tomarte un Hércules. De ir a la base y poder volar a cualquier lado y pedir ayuda para cualquier cosa (Entrevista a habitante de El Palomar).

Desde su fundación en 1910 El Palomar formó parte del crecimiento demográfico y urbano que el conurbano bonaerense experimentó durante la primera mitad del siglo XX, especialmente entre las décadas del 1940 y 1960. Su paisaje combinaba la presencia de quintas, chacras y tambos en lo que fueron las tierras cercanas a la estación del ferrocarril Buenos Aires al Pacífico, su primer núcleo urbano (Bocciardo, s/r; del Busto, 2003). Allí se instalaron las primeras organizaciones de vecinos desarrollando una densa trama asociativa de fomento barrial que hasta hoy ha dejado sus marcas en la vida comunitaria de la localidad y en la memoria de sus habitantes. 
En aquel entonces, aunque El Palomar pertenecía -como en la actualidad- al partido de Morón, se localizaba en su periferia, alejada de la ciudad cabecera del partido, lo que quizás explique que sus habitantes -constructores de sus propias viviendas en lotes sin servicios (Armus y Bohoslavsky, 2007)- se autopercibieran como residentes de la periferia de su propio municipio. Como sostiene una habitante: "éramos el último orejoncito del tarro porque estábamos en el límite con Tres de Febrero" (Testimonio de habitante de El Palomar, Taller de Historia Oral, organizado por el Archivo Histórico de Morón, 16 de junio de 2005).

El Partido de Morón, situado en la confluencia del Ferrocarril Buenos Aires al Pacífico (en la actualidad Ferrocarril Gral. San Martín) tuvo un importante crecimiento demográfico en especial entre 1914 y 1947, pasando de 24.624 a 110.344 habitantes, constituyendo el sexto partido más poblado del conurbano en los años 40. La población se concentró sobre todo en el espacio urbano, coherente con el perfil industrial que fue adquiriendo el distrito. En 1947, el 21\% de la población era extranjera (italianos, españoles y, en menor medida, franceses, ingleses y suizos), mientras entre los nacidos en Argentina, un 38\% no era de Buenos Aires, lo que indica un importante proceso de migración interna hacia el distrito. Para la década de 1970 Morón era el segundo partido con mayor cantidad de población de la provincia después de La Matanza (Vapñarsky, 2000). Entre las zonas más densamente pobladas estaba El Palomar junto con Haedo, Morón y Villa Sarmiento.

La nueva vida en el suburbio y sus demandas de progreso marcaron la agenda de las diversas juntas vecinales y asociaciones de fomento que se formaron desde los primeros años de fundación de la localidad. Estas entidades gestionaron ante las autoridades municipales y provinciales el alumbrado público mediante faroles a kerosén, el arbolado y la colocación de pasos de adoquín en las esquinas, las mejoras en las veredas de ladrillos, las alcantarillas y las zanjas de desagüe. A su vez, se involucraron en la gestión de la pavimentación de sus arterias principales donde circulaba un ómnibus, dos o tres veces por día. Además, impulsaron la creación de escuelas y el desarrollo de las comunicaciones instalando, por ejemplo, una estafeta postal (Bocciardo, s/r). Como expresa este testimonio de un habitante con más de 50 años en la localidad,

Sociedad de fomento y clubes peleamos mucho por el progreso de Palomar. $Y$ también nosotros le poníamos el hombro al municipio. Cuando asfaltaron hicimos tres asados en el Emaús. Se cooperaba mucho (Entrevista a habitante de El Palomar).

La llegada de contingentes poblacionales durante las décadas posteriores a 1920 densificó aún más esa trama asociativa vinculada al fomento, sumándose espacios recreativos, deportivos y de ocio. En 1926 se fundó el Club Atlético El Palomar, en 1934 se instaló la sede de la Sociedad Italiana de Tiro al Segno, en 1939 se fundó el Círculo Criollo El Rodeo de Caseros, que en 1948 se traslada a El Palomar, mientras en 1945 se abría la biblioteca popular Juan Manuel Giuffra. En 1954 se registran 65 Sociedades de Fomento reconocidas en Morón, la mayoría se encuentra en los nuevos barrios: El Palomar, Haedo norte, Castelar sur, Morón, Ituzaingó y Hurlingham (Saez y Birocco, 2010). La figura 5 es representativa de como la comunidad se sentía parte de un acontecimiento como el de la inauguración de una pileta de natación en el Club Atlético El Palomar. 


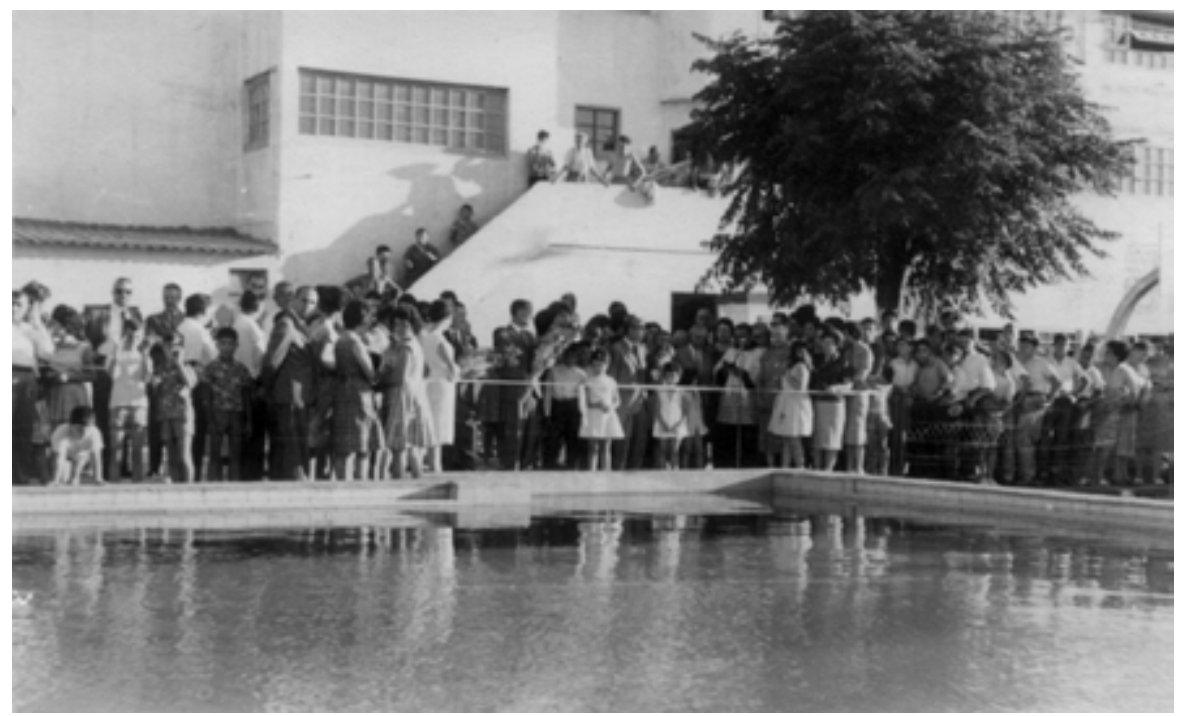

Figura 7. Inauguración de la piscina de Club Atlético de El Palomar. Fuente: Archivo Histórico de Morón. Circa 1940

La relación débil entre la localidad y el estado municipal se evidencia en numerosos decretos y ordenanzas municipales del partido de Morón de los años 40 y 60, los cuales constituyen la muestra significativa de una suerte de terciarización que ejercía el municipio en cuestiones vinculadas al desarrollo de servicios e infraestructura urbana. En dichas intervenciones, por ejemplo, se eximía del pago de impuestos municipales a buena parte de las organizaciones sociales antes aludidas.

En este sentido, es relevante hacer notar con qué y con quiénes se comparaban los habitantes de El Palomar. Entre 1940 y 1950, los palomarenses establecían un contraste con Ciudad Jardín Lomas del Palomar, una ciudad planificada provista de asfalto, agua corriente, cloacas, escuelas y espacios de esparcimiento (plazas, bares, confiterías, cine), cuartel de bomberos, sala de primeros auxilios, estación de policía y calles pavimentadas. Otro, respecto de Morón (la cabecera del partido), que saltaba a la vista cuando tenían que ir allí, por ejemplo, para realizar algún tipo de trámite municipal. Su acelerado proceso de renovación urbana -adoquinado de calles, arbolado, nivelación de veredas, construcción de plazas, extensión de alumbrado de mercurio y la edificación del Palacio Municipal-, contrastaba con las infraestructuras más precarias de su distrito periférico y menos atendido por el Estado. 


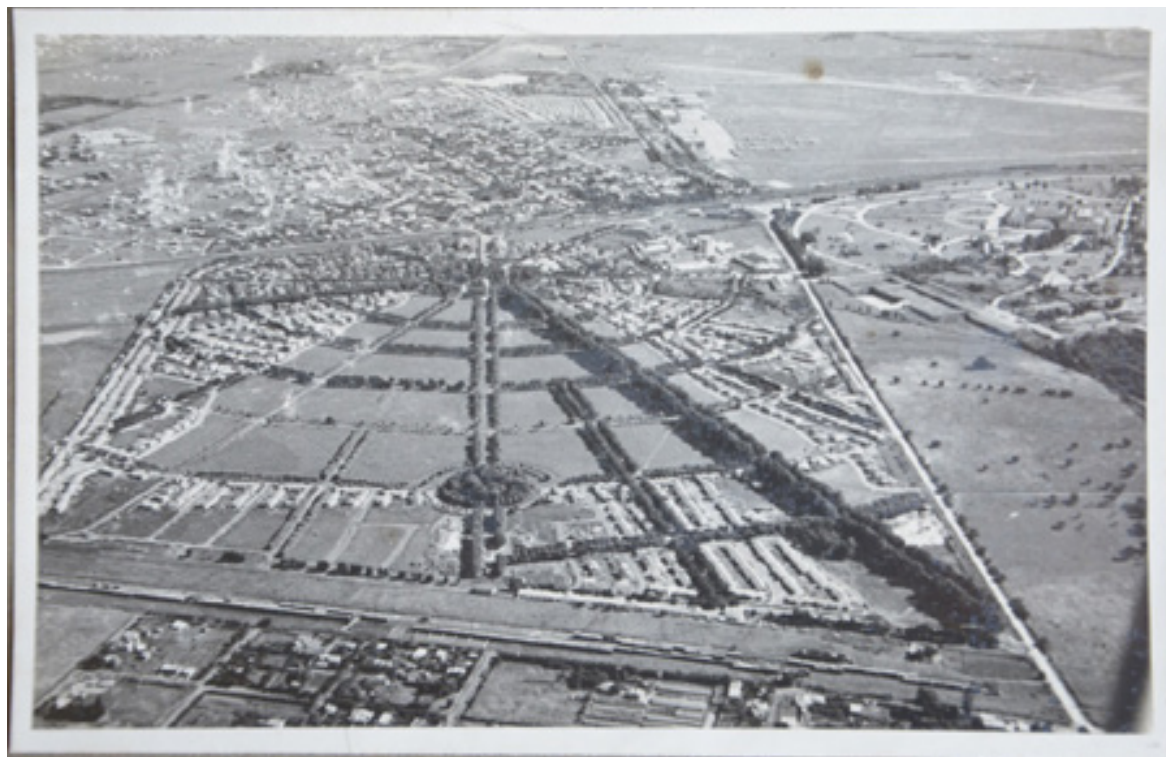

Figura 8. Foto aérea de El Palomar, Ciudad Jardín y Martín Coronado. Fuente: Archivo Selig. Circa 1952

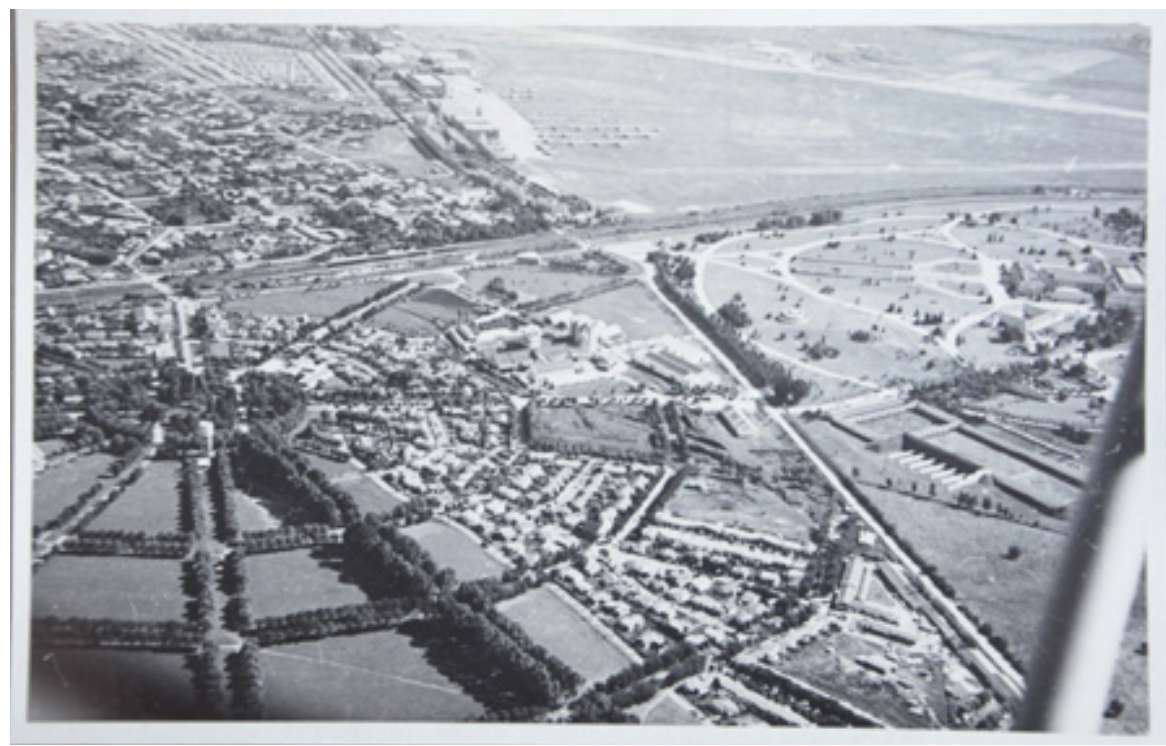

Figura 9. Foto aérea de El Palomar, Ciudad Jardín y Martín Coronado. Fuente: Archivo Selig. Circa 1952 


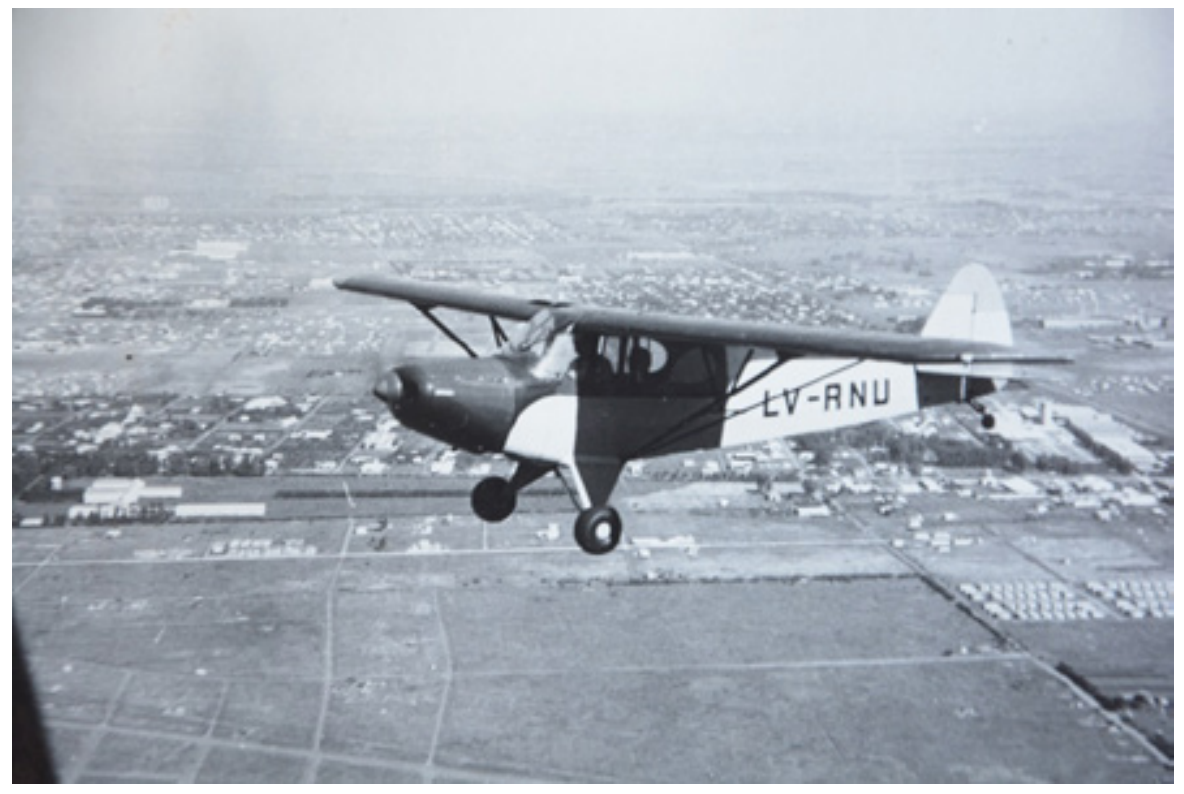

Figura 10. Sobrevuelo por el conurbano oeste. Fuente: Archivo Selig. Circa 1954

En este contexto, el de una suerte de territorio de frontera, la presencia de la Base Aérea fue crucial en la construcción de un lugar. En las figuras 8 y 9 se advierte la impronta de estas infraestructuras en el territorio. A la derecha, en ambas, se ve la instalación aeronáutica y el barrio aledaño que alojaba a su personal y el Colegio Militar. Los testimonios de los habitantes mayores y memoriosos y de sus hijos son elocuentes:

(...) con la Base, me saco el sombrero (Entrevista a habitante de El Palomar).

La Base nos venía a pintar los árboles todos los años con cal y arreglaba las calles y las veredas (Testimonio de habitante de El Palomar, Taller de Historia Oral, organizado por el Archivo Histórico de Morón, 16 de junio de 2005).

La Base permanentemente estaba para lo que necesitábamos. En aquel tiempo teníamos militares que iban y venían y volaban. Vos ibas a la base, coordinabas y te tomabas un avión (Entrevista a habitante de El Palomar).

En efecto, la Base Aérea asumió en los hechos y en percepciones de los habitantes, el espacio que dejaba vacante el estado municipal en el hacer el barrio: convertir esta mezcla de ámbito rural y zona industrial en un territorio que permitiera y alentara la integración social y urbana de sus habitantes.

Vivir cerca de la Base resultó un activo significativo del capital espacial de los habitantes de la localidad (Levy, 2003), tan importante como el hecho de vivir cerca de la estación del ferrocarril. No es casual que las loteadoras de la época pusieran en valor ambos elementos: la presencia de la Base y de la conectividad con el centro que el ferrocarril ofrecía. Un folleto de 1943 de la inmobiliaria Astoul Bonorino \& Cía. ofrecía así sus casi 160 lotes:

Pavimentos existentes pagos, servicios de colectivos, muy próximos a la estación y frente por frente a la Escuela Militar de Aviación, barrio ya hecho, con toda clase de adelantos yencerrados entre nuevas construcciones, que han cambiado esta enorme fracción en un barrio populoso y con vida propia. Son los terrenos más baratos que se ofrecen en la zona, siendo especiales no solo para la construcción de la casa propia, sino también se recomiendan especialmente como la mejor Caja de Ahorros. 
Por otra parte, la presencia de la Base fue central para la provisión de servicios sociales. Hasta 1950 y dada la falta de atención sanitara en la zona, los habitantes usaban el servicio de enfermería y el hospital militar de la Base. Más adelante, y con la colaboración de los vecinos y los militares de la Base, se construyó una casa de madera y chapa donde funcionó la sala de primeros auxilios de El Palomar, a la que tiempo después y luego del reconocimiento del Ministro de Salud Pública de la Provincia, les fueron otorgados algunos medicamentos y elementos médicos (Saez y Birocco, 2010; Bocciardo, s/r).

La comunidad recorría y usaba en forma cotidiana el espacio de la Base y sus terrenos lindantes. Una vecina, cuyo padre estuvo involucrado en la fundación de una de las organizaciones emblemáticas de El Palomar, la Biblioteca Juan Manuel Giuffra (aquella en la que se llevó a cabo una de las audiencias públicas que se menciona al comienzo del artículo), comenta:

Los chicos pescaban en una fosa cerca del Colegio Militar o un arroyo en el cruce donde cruza el tren. Otro entretenimiento era ver los aviones, los pilotos los llevaban a volar (Entrevista a habitante de El Palomar).

A su vez, la Base tuvo un rol activo en el ámbito educativo: apadrina escuelas, transporta a los estudiantes en los días de lluvia o presta sus instalaciones para la organización de eventos. De hecho, la institución donó terrenos para la instalación de una de las escuelas primarias de la localidad y permitió que los scouts desarrollaran allí sus actividades. En la Figura 9 se aprecia un conjunto de dibujos exhibidos en las aulas de la Escuela no 5 T. Benjamín Matienzo. Se trata de escenas alusivas a la Base Aérea que, según el relevamiento mediante el trabajo de campo, son de 1946, de autor anónimo, por encargo del Ministerio de Educación en ocasión de la inauguración del nuevo edificio de la escuela.

Sin la misma intensidad, la función de pilar del desarrollo comunitario ejercido por la Base sigue activa en el presente. El 29 de abril de 2018 un temporal provocó caída de árboles, inundaciones en calles y destrozos en general. En las noticias se mostraba la dramática situación de la escuela Matienzo que había perdido gran parte de su techo con el fuerte viento. Una habitante de la localidad señalaba "la Base fue la primera en llegar". Otro residente entrevistado unos días después del evento comentó que el día del temporal, él junto con los padres de familia, estudiantes y vecinos, con el agua hasta las rodillas, recibieron la ayuda "inmediata, durante esa misma noche, de la Base que mandó hombres que ya salían de su turno a trabajar en la escuela, además de máquinas para sacar el agua".

Una semana después la escuela era noticia nuevamente, cuando la gobernadora visitaba sus instalaciones para evaluar la gravedad de los daños (La Nación abril 2018). Durante unos meses, se acondicionó un espacio en la Base para el funcionamiento de la escuela.

Este episodio da cuenta de la persistente intensidad de los vínculos entre la población de El Palomar y la Base aérea, así como de la figura de estatidad que impone esta institución en el juego de presencia-ausencia del Estado provincial y municipal. Un habitante relata:

(...) a partir de entonces hubo que esperar a las autoridades municipales y provinciales que aparecieron e iniciaron la obra de reconstrucción, pero pasaron varios días para eso, cuando la Base estaba dispuesta e incluso a poner en los techos parte de la pintura que usaban en las pistas. 

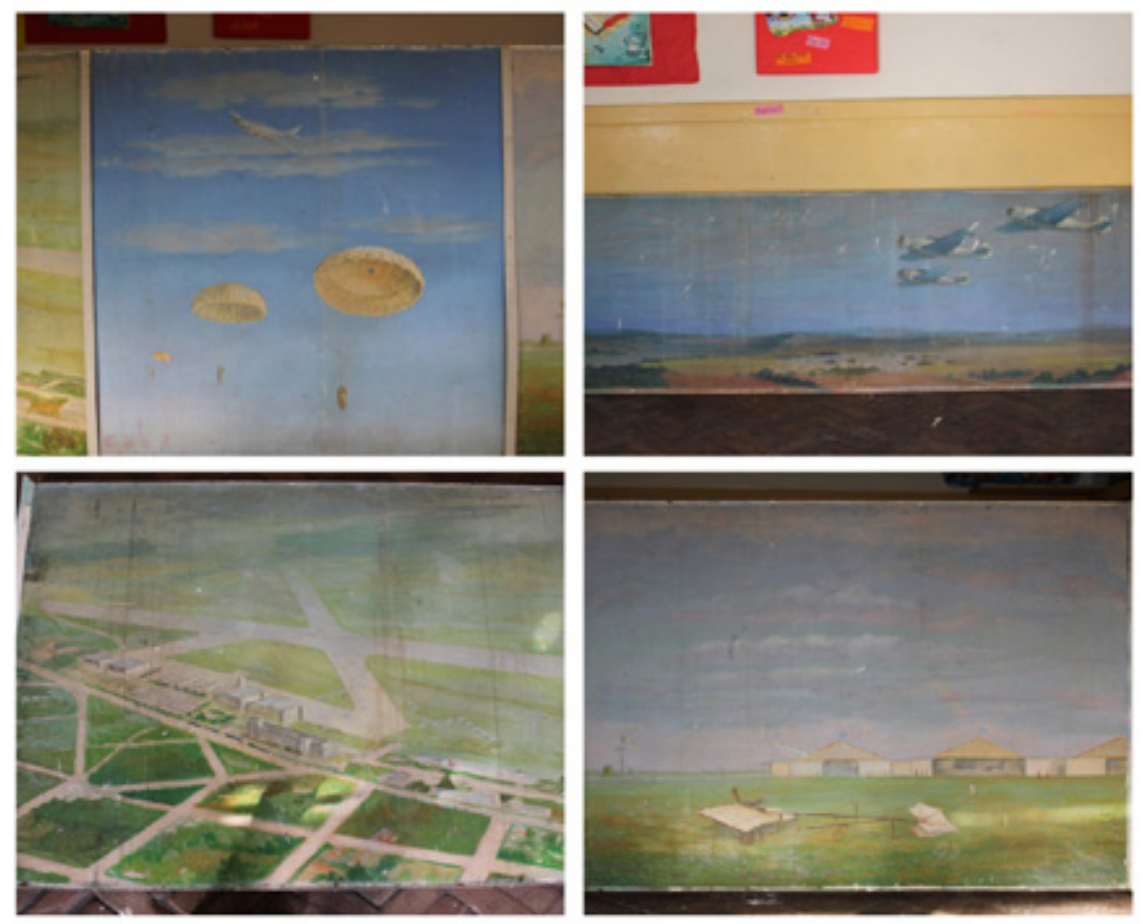

Figura 11. Fotografías de los dibujos de 1946 salvados de la inundación de 2018. Escuela nº 5 T. Benjamín Matienzo. Fuente: Trabajo de campo (2018)

Los vínculos, no obstante, son polémicos. Para los directivos de la institución la Base no tenía que cumplir este rol. Buena parte de estos argumentos cuestionan la naturaleza militar del "aliado", por sus responsabilidades en las violaciones a los derechos humanos sucedidos en la última dictadura militar.

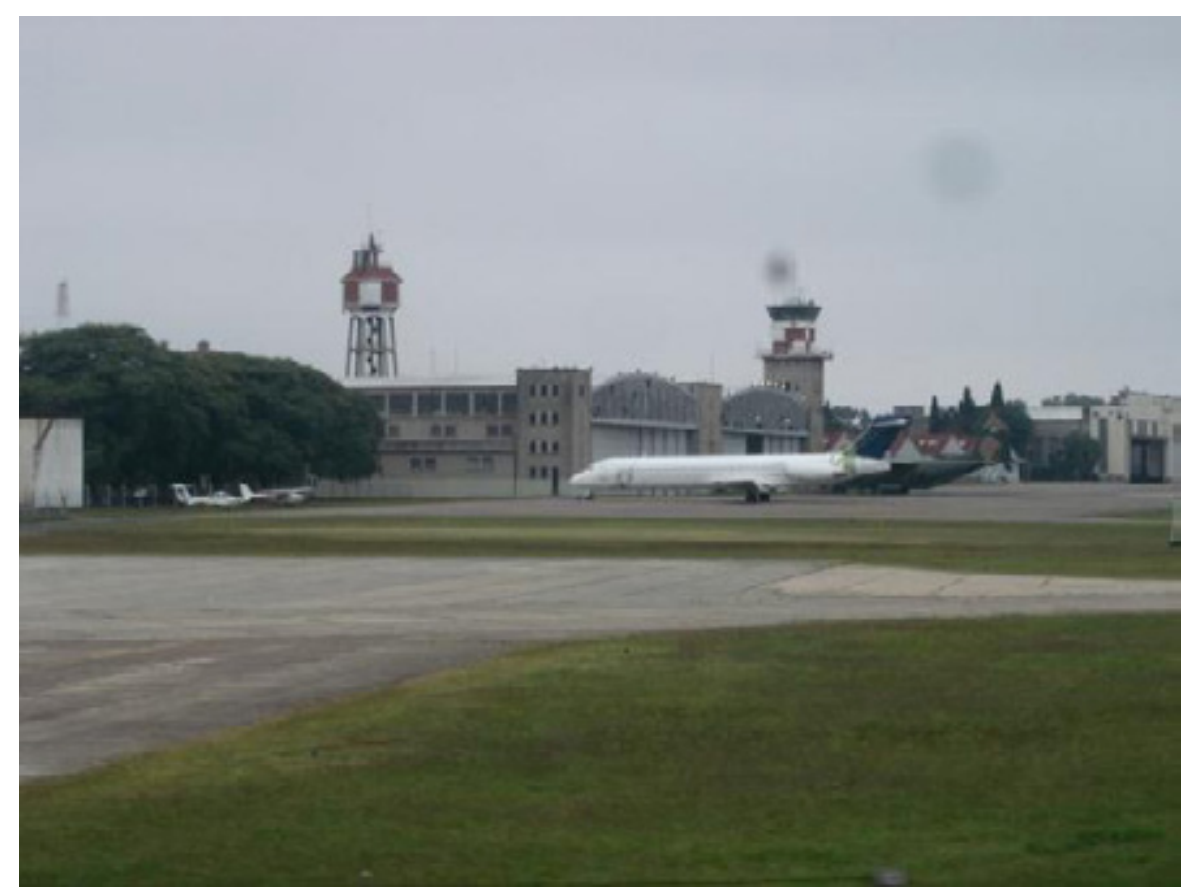

Figura 12. Instalaciones de la Base Aérea vistas desde el Tren San Martín. Fuente: Trabajo de campo (2014). 


\section{Reflexiones finales}

En los paisajes se lee la historia pasada y presente, se sintetiza la evolución de los lugares y de sus gentes y se integran estados sucesivos e intervenciones diversas. Es lo que algunos han comparado con un "palimpsesto" o un "paisaje milhojas", y la labor de descodificar el paisaje supone eso: ir leyendo las diferentes capas que lo componen, tanto las materiales como las espirituales y simbólicas, al igual que las distintas escrituras que el hombre va superponiendo a lo largo de la historia (Cabrerizo y Rodríguez, 2010:190).

Si el investigador de la trama cultural urbana toma la invitación del epígrafe y arriba a la localidad de El Palomar, advertirá a poco de andar que el aeropuerto comercial interpela con grados variables de intensidad un fuerte imaginario suburbano y su paisaje. Como se vio, la Base aérea fue funcional históricamente a la constitución del territorio, no sólo a través de acciones mancomunadas con las organizaciones comunitarias, sino también ocupando el lugar de la autoridad frente a un gobierno local débil y provincial muy lejano. Su naturaleza militar y jurisdiccional nacional contribuiría a resguardar el carácter externo, solemne y estoico de sus intervenciones frente a los problemas cotidianos del desarrollo.

En la actualidad, la mercantilización que trajo la autorización de los vuelos comerciales en sus instalaciones desafía esta impronta, al subvertir ese viejo pacto de la geopolítica local. Nuevos actores e intereses pujan por acumular poder político y económico en este territorio y las posiciones -tanto críticas como favorables- de los residentes reinscriben el juego local en la escena política nacional.

Asimismo, en el paisaje se produce una suerte de embellecimiento sobre el deterioro, una modernización desconectada del pasado. Sobre la postal de milhojas que mostraba El Palomar-cartelerías y marquesinas herrumbradas, fachadas despintadas- se instalan nuevos artefactos que traen otras ideas de ciudad, movilizando a los imaginarios y modelando nuevos paisajes visuales urbanos (Reguillo, 2001). 4

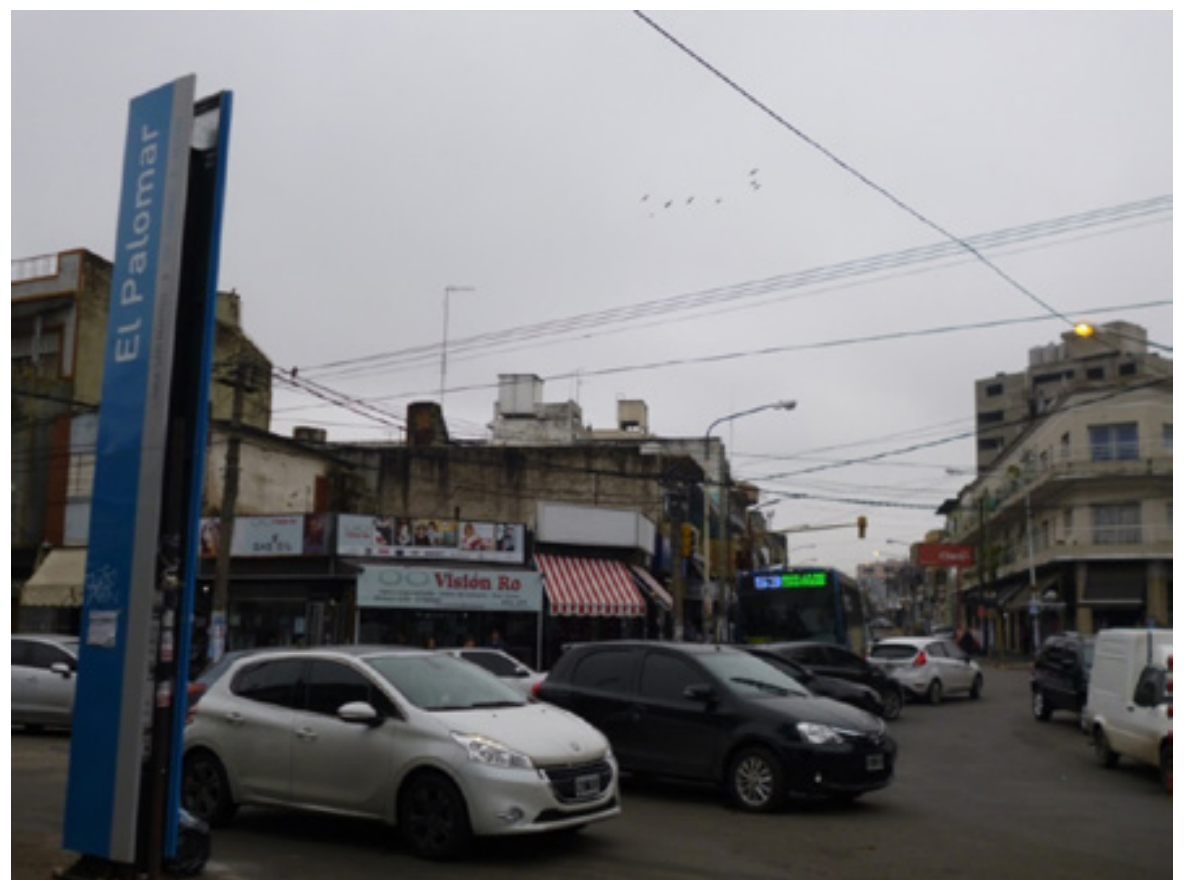

Figura 13. Avenida Marconi, zona comercial de El Palomar. Fuente: Trabajo de campo (2015).
4. El concepto de paisaje remite a la unidad de territorio - más o menos bien definida- , que varía en función de quien lo mira y del lugar de observación, pero sobre todo de las representaciones que comparten los miembros de una cultura. De este modo, la vinculación entre paisaje y subjetividad en un sentido experiencial o vivencial, se torna crucial en el estudio de las ciudades. (Alvarez Muñarriz, 2011) 


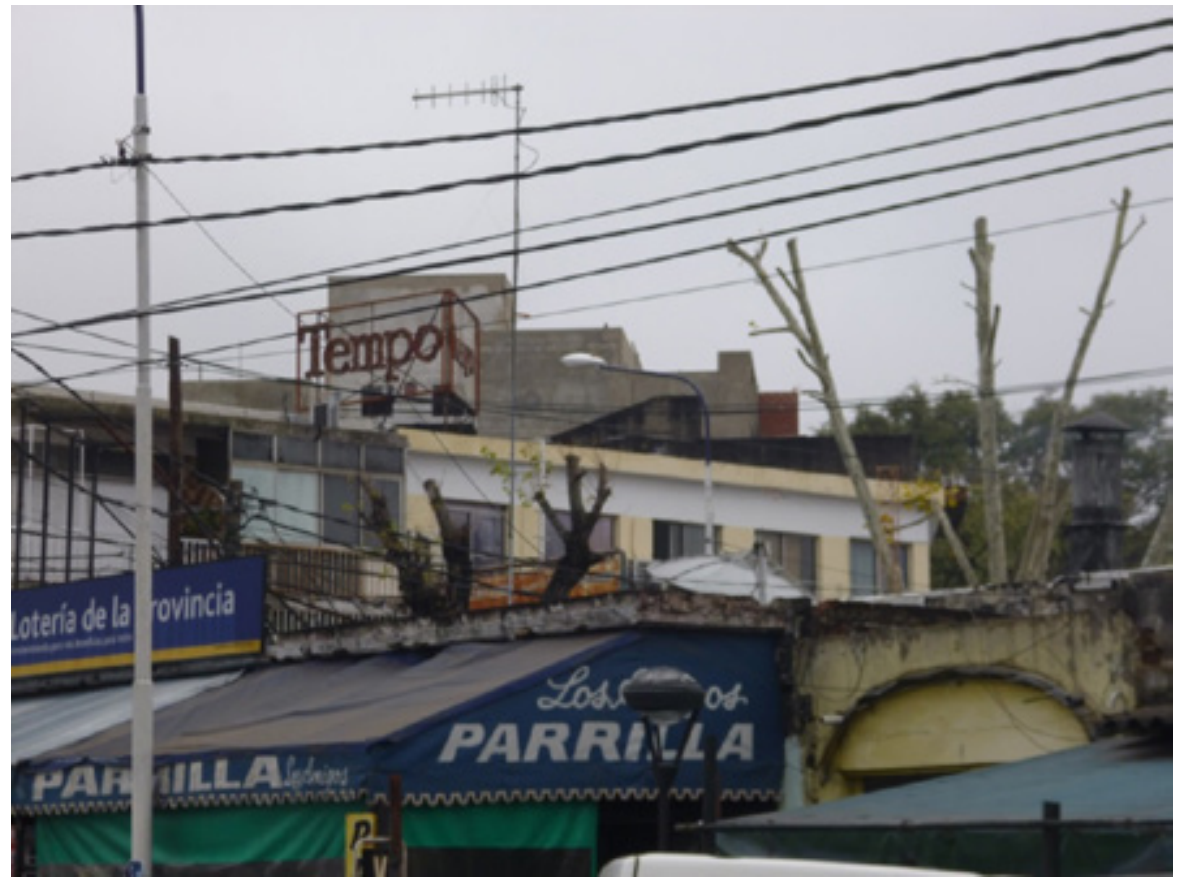

Figura 14. Avenida Marconi, zona comercial de El Palomar. Fuente: Trabajo de campo (2015)

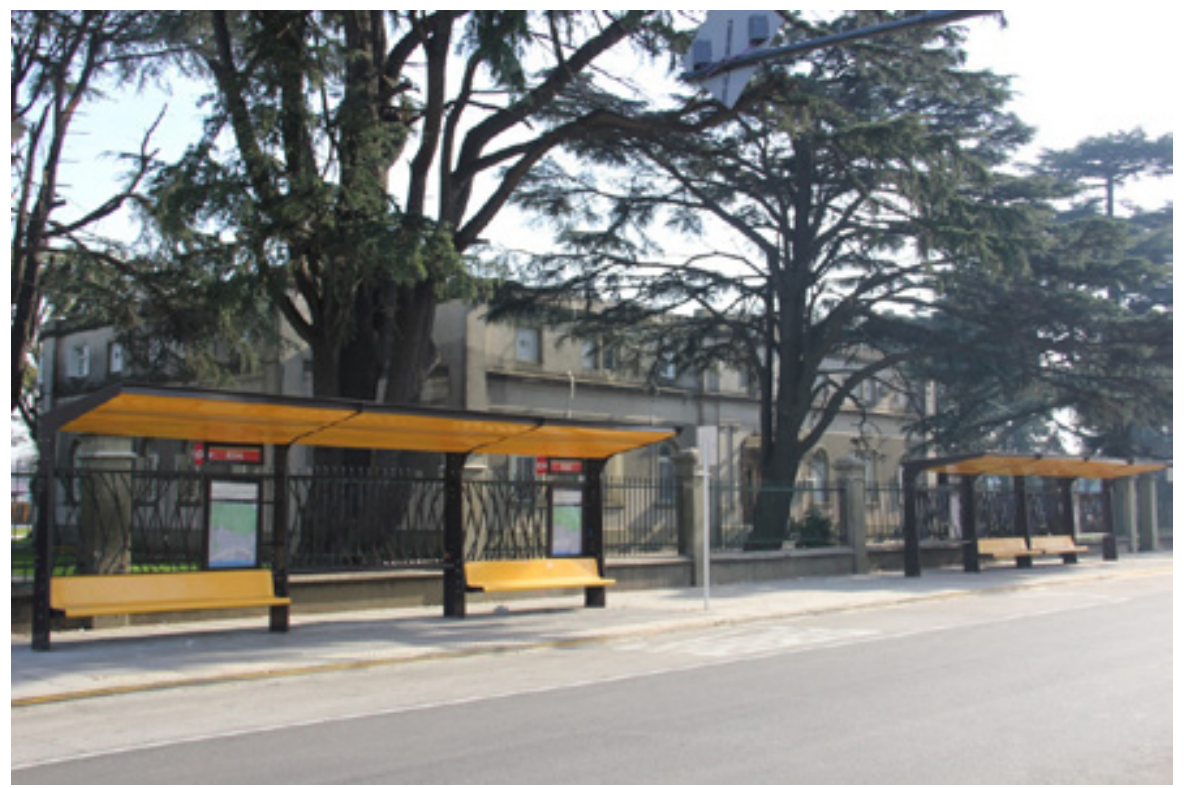

Figura 15. Nuevas paradas de transporte urbano sobre la entrada de la antigua Base, en la actualidad Aeropuerto de El Palomar. Fuente: Trabajo de campo (2018)

Por ello, el análisis de las disputas en torno al aeropuerto en clave de un dualismo conservación-modernización no hace justicia con la historia. El Palomar creció con esta infraestructura en su núcleo, y eso complejiza la dicotomía. En efecto, si los portadores del primer argumento se oponen a los cambios en nombre de la tradición, no podrán eludir el hecho de que desde el momento fundacional el territorio estuvo marcado por la idea de progreso, innovación y, por qué no, modernización y conexión con el mundo exterior. Como se argumentó en este trabajo, si algo ha caracterizado a El Palomar desde su conformación fue ese rasgo distintivo, que le servía además para procurar contrarrestar su condición de periferia relativa y reivindicarse frente a las localidades 
vecinas que contaban con mejor calidad de vida. En otras palabras, la Base fue clave en ese momento germinal para construir la identidad de una localidad que, a pesar de la indiferencia estatal, contaba con un relato de modernidad y progreso.

Esto mismo es lo que convierte, paradójicamente, a los modernizadores en los conservadores más fieles, ya que, quizá sin saberlo o reconocerlo y, aunque guiados por objetivos mercantiles, son los que mejor recogen esa tradición de lugar conectado al mundo, que ahora revive de las cenizas a las que la había condenado la serie de crisis económicas argentinas de las últimas décadas, de la mano del proyecto del aeropuerto comercial. Lo que pase con el reciente despertar del monstruo dormido -testigo silencioso de un conurbano en permanente mutación- es una enorme y compleja pregunta abierta al futuro.

\section{Agradecimientos}

Las autoras agradecen a Adriana Sánchez por el trabajo de investigación histórica, a Marcela Deliberis por la realización de los planos y la colaboración en el análisis espacial y a Eduardo Gallardo, Patricia Cuccaro, Francisco Selig y Sociedad de fomento "El Palomar". Este artículo se inscribe en el proyecto de investigación "Sociabilidades suburbanas, movilidad cotidiana y consumos. Para una investigación cultural del Conurbano Bonaerense" (Instituto del Conurbano, UNGS) y sus líneas de indagación forman parte del libro en elaboración El otro Conurbano. Experiencias y sociabilidades de las clases medias (1930-1970). 


\section{Q Bibliografía}

"Armus, D. y Bohoslavsky, E. (2007). Vivienda popular y asociacionismo en la conformación del Gran Buenos Aires. En G. Kessler (comp.), Historia de la Provincia de Buenos Aires 6 (493-520). Buenos Aires: Argentina: UNIPE-EDHASA.

"Alvarez Muñarriz, L. (2011). La categoría de paisaje cultural. AIBR. Revista de Antropología Iberoamericana 6(1), 57-80.

»Bocciardo, A. (s/f). El Palomar, su historia. Buenos Aires: Argentina. inédito.

»Brubaker, R. y Cooper, F. (2001). Más allá de identidad. Apuntes de Investigación del CECYP (7).

»Cabrerizo Sanz, C. y Rodríguez Chumillas, I. (2010). Ciudad y territorio en clave de paisaje urbano contemporáneo en España y México. Cuadernos de Vivienda y Urbanismo 3 (6), 182-195.

»Ebe del Busto, A. (2003). El Palomar: Memorias, recuerdos y olvidos, Duodécimo Congreso nacional y regional de historia argentina, Buenos Aires, Argentina.

"Delgado, M. (2011). El espacio público como ideología. Madrid: Los libros de la Catarata.

" Gravano, A. (2006). El barrio en la teoría social. Buenos Aires: Espacio Editorial.

» Gualteros Trujillo, J. N. (2006). Itinerarios urbanos. París, La Habana, Bogotá: narraciones, identidades, cartografías. Bogotá: Universidad Javeriana-Cuadernos Pensar.

"La izquierda Diario (2018). De la Redacción. Recuperado de https:// www.laizquierdadiario.com/Vecinos-de-El-Palomar-marcharon-contra-elaeropuerto-trucho (15/10/2018).

»LMNeuquén, De la Redacción. (2018, julio 11). Flybondi canceló vuelos y los pasajeros estallaron en furia. LMNeuquén. Recuperado de https://www. Imneuquen.com/flybondi-cancelo-vuelos-y-los-pasajeros-estallaron-furiatuvo-que-intervenir-la-policia-n598488 (25/09/2018).

»La Nación, De la Redacción. (2018, marzo 28). Insultos y empujones en la audiencia pública por las obras en El Palomar (2018, marzo 29). La Nación. Recuperado de https://www.lanacion.com.ar/2121354-audiencia-publica-obraaeropuerto-el-palomar (30/06/2018).

»La Nación, De la Redacción. (2018, abril 29). Tormenta eléctrica en Buenos Aires: granizo, destrozos e inundaciones. La Nación. Recuperado de https:// www.lanacion.com.ar/2130166-tormenta-electrica-en-buenos-aires-destrozose-inundaciones-por-la-lluvia-el-granizo-y-las-fuertes-rafagas-en-la-madrugada (22/07/2018).

» Lévy, J. (2003). Capital spatial. En J. Lévy y M. Lussault, (eds.). Dictionnaire de la géographie et de l'espace des sociétés. Paris, France: Belin.

» Municipio de Morón (2018) Gobierno de Morón, corazón del oeste. Pavimentación de calles. [Sitio oficial del municipio] http://www.moron.gob. ar/nuestra-gestion/obras/planeamiento-urbano/redes-e-infraestructura/ pavimentacion. Recuperado el 25/04/2018.

»Portal Información Hurlingham. De la Redacción. (2018, abril 23). Hurlingham: 
escuelas denuncian contaminación ambiental por vuelos de Flybondi. Portal Información. Recuperado de http://portalinformacion.com/index. $\mathrm{php} / 2018 / 04 / 23 /$ hurlingham-escuelas-denuncian-contaminacion-ambientalvuelos-flybondi/ (20/10/2018).

» Reguillo, R. (ed.) (2001). Lotería urbana: un juego para pensar la ciudad. Guadalajara: Iteso.

»Saez, G. L. y Birocco, C. M. (2010). Morón, de los orígenes al bicentenario. Morón, Argentina: Municipalidad de Morón.

"Soldano, D. y Perret Marino, G. (2017). El otro conurbano. Experiencias y sociabilidades de las clases medias en la conformación de tres localidades del Gran Buenos Aires (1940-1960). Anales del IAI 47 (I), 125-146.

"Soldano, D. y Perret Marino, G. (2017). Viajes y experiencias del espacio en los bordes de la ciudad. En D. Soldano (comp), Viajeros del Conurbano Bonaerense. Una investigación sobre las experiencias de la movilidad y el espacio en los bordes de la ciudad (173-221). Los Polvorines: Ediciones UNGS.

»Subra, P. (2012/3). La géopolitique, une ou plurielle ? Place, enjeux et outils d'une géopolitique locale. Hérodote 3-4 (146-147), 45-70.

»Silva, A. (2008). Los imaginarios nos habitan. Quito: Olacchi.

»Vapñarsky, C. (200o). La aglomeración Gran Buenos Aires. Expansión espacial y crecimiento demográfico entre 1869 y 1991. Buenos Aires: Eudeba.

\section{Fuentes}

»Archivo Histórico de Morón. Caja Palomar.

"Archivo Fotográfico de Francisco Selig

»Decretos y ordenanzas municipio de Morón, 1938-1962 (selección).

\section{Daniela Soldano / da.soldano@gmail.com}

Licenciada en Ciencia Política por la Universidad de Buenos Aires (UBA), magíster en Política Social, Facultad Latinoamericana de Ciencias Sociales (FLACSO) y doctora en Ciencias Sociales (UBA). Profesora titular de la Universidad Nacional del Litoral (UNL) e investigadora docente adjunta en el Instituto del Conurbano de la Universidad Nacional de General Sarmiento (ICO/UNGS). Actualmente, dirige el proyecto "Sociabilidad suburbana, movilidad cotidiana y consumos" (ICO/UNGS).

\section{María Gimena Perret Marino / gimenaperret@gmail.com}

Profesora en Ciencias Antropológicas por la Universidad de Buenos Aires (UBA) y doctora en Ciencias Antropológicas (UBA) con especialización en Antropología Política y Cultural en la Facultad Latinoamericana de Ciencias Sociales (FLACSO). Estudios de maestría en Política y Gestión de la Ciencia y la Tecnología (UBA). Docente del Ciclo Básico Común (CBC) de la UBA e investigadora docente regular en la Universidad Nacional de General Sarmiento (UNGS). Actualmente, integra el proyecto "Sociabilidad suburbana, movilidad cotidiana y consumos" (ICO/UNGS). 